\title{
Changes in the Optical Properties of Simulated Shuttle Waste Water Deposits - Urine Darkening
}

Keith Albyn, and David Edwards, NASA, George C. Marshall Space Flight Center, Huntsville, Alabama 35812

John Alred, Boeing Space Station Program Office Houston, Texas 77058

\begin{abstract}
Manned spacecraft have historically dumped the crew generated waste waster overboard, into the environment in which the spacecraft operates, sometimes depositing the waste water on the external spacecraft surfaces. The change in optical properties of wastewater deposited on spacecraft external surfaces, from exposure to space environmental effects, is not well understood. This study used nonvolatile residue (NVR) from Human Urine to simulate wastewater deposits and documents the changes in the optical properties of the NVR deposits after exposure to ultra violet (UV) radiation. Twenty four NVR samples of, 0-angstromes $/ \mathrm{cm}^{2}$ to 1000 -angstromes $/ \mathrm{cm}^{2}$, and one sample contaminated with 1 to $2-\mathrm{mg} / \mathrm{cm}^{2}$ were exposed to UV radiation over the course of approximately 6151 equivalent sun hours (ESH). Random changes in sample mass, NVR, solar absorbance, and infrared emission were observed during the study. Significant changes in the UV transmittance were observed for one sample contaminated at the $\mathrm{mg} / \mathrm{cm}^{2}$ level.
\end{abstract}




\section{Nomenclature}

ESH $=$ Equivalent Sun Hours

FTIR = Fourier transform infrared spectroscopy

UV/VIS = Ultra Violet/Visible Radiation (200-nm to 2500-nm)

UV = Ultra Violet Radiation 200-nm to 400-nm

NVR $=$ Nonvolatile Residue $\mathrm{mg} / \mathrm{cm}^{2}$

\section{Introduction}

The Mir Environment Exposure Payload (MEEP), which included flight experiments such as the Polish Plate Meteoroid Detector (PPMD) and the Passive Optical Sample Assembly II (POSA-II), were delivered to the Russian Space Station Mir aboard Space Transportation System (STS)-76 and returned to earth aboard STS-86. The experiments, mounted in Passive Experiment Containers (PEC's), were exposed to the Mir external environment for 18-months during which time four Shuttle flights approached and docked with Mir. Post-flight inspection of the external PPMD and POSA-II surfaces reveled deposits of material that, from the pattern of the NVR deposits, appeared to have been a liquid when the material contacted the surfaces of both the PEC's and the experiments.

Chemical analysis of the deposited material detected inorganic salts that are commonly found in human urine, suggesting that waste water released into the external Mir environment was the source of the contaminant. To document and quantify the effect of UV on simulated wastewater, a study was conducted as a joint effort between the George 
C. Marshall Space Flight Center (MSFC) and the Lyndon B. Johnson Space Flight Center (JSC). The study tracked the changes in the trasmittance, 200-nm to $2500-\mathrm{nm}$, of urine deposits after multiple UV exposure intervals totaling approximately 6151-ESH of UV exposure.

\section{Method}

Fused silica disks, 2.54-cm diameter, were used as the substrate on which the simulated wastewater NVR was deposited. This material was selected based on its optical transmittance, 170 to $2500-\mathrm{nm}$, and the chemical inertness of the silica (Figure 1).

Figure 1. Ultra Violet/Visible Light (UV/VIS) Spectrometer scan of the fused silica substrate $200-\mathrm{nm}$ to $2500-\mathrm{nm}$. Ambient laboratory air was used as the background for the scan.

To increase the amount of sample solution that could be applied to a substrate in a single application, and to insure uniform "wetting" of the entire substrate surface, a wall or dike was formed around the edge of each substrate using Kapton tape (acrylic adhesive). This modification allowed 1.0-milliliter of the sample solution, containing the desired amount of material, to uniformly "wet" the entire substrate surface. The tape was then removed from the substrate after the solution had evaporated. The same Kapton tape was applied to the surface of two substrates, samples $\# 19$ and $\# 20$, prior to the application of the urine solution. This layer of Kapton was intended to be a low fidelity simulation of the Kapton substrate of the International Space Station, Solar Arrays. The procedure for the 
application of the urine solution to these samples was the same as all of the other samples.

\section{Simulated Waste Water/Urine}

The urine used in the study is commonly use as an analytical standard by medical laboratories and was purchased from Bio-Rad Laboratories as a dehydrated material $\left({ }^{*}\right.$ Lyphocheck $\left.^{\mathrm{R}}\right)$. A density of 1.0-gram per cubic centimeter was assumed for the material, which was re-hydrated using $18 \mathrm{meg-ohm}$ water. A "stock solution of $5.1 \times 10^{-5}$ grams $/ \mathrm{ml}$ (1000 Angstroms $/ \mathrm{ml}$ ) was prepared and serial dilutions of this solution made. The concentration of urine, in the serial dilutions, was calculated to produce the desired NVR level (angstroms $/ \mathrm{cm}^{2}$ ) when $1.0 \mathrm{ml}$ of the solution was placed on the substrates. The sample solutions were prepared immediately before application of the solution to the fused silica substrate and once applied to the substrates, allowed to air dry in a laminar flow bench, that provided a clean environment for the drying process.

Preliminary optical and mass measurements were made on all 24 samples to document the initial properties of the samples prior to UV exposure. A review of the measurements could not find any significant differences between clean substrates and those with NVR deposits (Figure 2). Additional ellisipsometery measurements also failed to detect material on the substrates.

* Lyphochek@ is a lypholized human urine-based quality control product marketed by Bio-Rad Laboratories of Hercules, $\mathrm{Ca}$. 
Figure 2. Samples \#15 and \#17 prior to UV exposure.

Since measurable differences in the samples could not be demonstrated, two "grossly contaminated" samples were prepared by JSC to insure that the study did contain a sample for which the initial optical properties could be measured. The same methods used to create the initial 24 samples were used to create two samples contaminated at the milligram $/ \mathrm{cm}^{2}$ level. One of the substrates was a $2.54-\mathrm{cm}$ diameter zinc selenide disk, which was used to confirm the presence of the urine deposit on the substrate by Fourier, transform infrared spectroscopy (FTIR). The other substrate was a fused silica disk identical to, and purchased with, the substrates used to create the original 24 samples. This sample was labeled JSC-B and the NVR deposit could be seen on the surface of the substrate. The presence of the NVR was also confirmed spectroscopically by the UVVIS scan (200 to 2500-nm) of this sample (Figure 3).

Figure 3. UV/VIS Scan of sample JSC-B prior to UV exposure.

\section{MSFC UV Exposure Facility}

The vacuum chamber, in which the exposure of the samples to ultra violet radiation was carried out, was assembled by MSFC for this study. The vacuum chamber is evacuated by a 470-liter/second turobomolecular pump, that is backed by a direct drive roughing pump, capable of evacuating the chamber to a hard vacuum $\left(<10^{-6}\right.$ torr $)$. The chamber is constructed of stainless steel and has a $19.5-\mathrm{cm}$ diameter, UV-transparent, viewing port through which the samples were illuminated. 
The samples were mounted on an aluminum sample holder (Figure 4) that was bolted to an actively cooled fixture in the vacuum chamber. The samples were maintained at 20 degrees Celsius during the exposure periods by the circulation of chilled water through the mounting fixture

The samples were illuminated with a Mercury Xenon lamp (200 to 2500-nm (UV-VIS)) positioned 74-cm away from the outer surface of the UV transparent, chamber viewing port. During the exposure periods the intensity of the UV at the surface of the viewing port was checked with a hand held radiometer. The silicon, photo diode radiometer has a flat response filter, combined with a "wide eye" diffuser, providing a "flat" spectral response from 410 to $1000 \mathrm{~nm}$. With the vacuum chamber at ambient pressure (laboratory atmosphere), the measured incident light at the sample holder, $2.2 \mathrm{~mW} / \mathrm{cm}^{2}$, was 61.1 percent of the light intensity measured at the surface of the viewing port. The sample holder is located $27-\mathrm{cm}$ behind the outer surface of the viewing port.

Figure 4. The sample holder with the fused silica sample disks as they appeared after approximately $6151 \mathrm{ESH}$ of UV exposure. On the left-hand side of the sample holder (9 and 10 o'clock positions) are samples \#19 and \# 20. The dark sample at the upper right-hand side of the sample holder (1 o'clock) is Sample JSC-B.

Figure 5. UV Lamp Spectrum. Major peaks at $304 \mathrm{~nm}, 315 \mathrm{~nm}$, and $376 \mathrm{~nm}$ 


\section{UV Lamp Failure}

During the exposure period of 1775 to $2566 \mathrm{ESH}$ the UV lamp failed, terminating the illumination of the samples. No rational for the failure, such as a facility power failure, was identified and the lamp functioned normally when re-started. Prior to the lamp failure, the output from the UV lamp was measured at the beginning and conclusion of each exposure period. The frequency of these measurements was increased to a daily measurement to insure that another lamp failure would be detected before the end of an exposure period. Based on the measure change in UV transmittance of the sample JSC-B (Figure 6), it is believed that the lamp failure occurred early in this exposure period. The sample exposure was extended beyond $4000 \mathrm{ESH}$ to compensate for the lamp failure and the total exposure time, $6151 \mathrm{ESH}$, could be reduced by as much as $789 \mathrm{ESH}$.

Figure 6. Scans of JSC-B prior to and after the UV-lamp failure.

Discontinued Measurements

In addition to UV/VIS transmittance measurements, the original study protocol included the weighing of the samples, measurement of the solar absorbance $(200 \mathrm{~nm}$ and $2800 \mathrm{~nm})$ and the measurement of the infrared emittance (2000 to 20000-nm) of the samples after each exposure period. After the first three exposure periods of 100-ESH, 358-ESH, and 
716-ESH, only random fluctuations were recorded for these parameters and no significant change from the pre-exposure values were observed. After the measurements at 716-ESH, no future mass, solar absorbance, or infrared emittance measurements were made until after the final UV exposure. After approximately $6151 \mathrm{ESH}$ of UV exposure no significant change in these parameters were measured.

\section{UV/VIS Spectrometer Measurements}

A Perkin-Elmer Lambda-19 UV/VIS Spectrometer was used to measure the changes in transmittance of the samples over the spectral range of 200 to $2500-\mathrm{nm}$. The preexposure measurements, transmittance and reflectance, failed to show any difference between the spectrum of the bare substrates and those with the NVR deposits (Figures 2). Sample JSC-B did have a unique transmittance spectrum, which was attributed to the substantial NVR deposit on the substrate.

\section{General Discussion}

Substrate darkening

The transmittance of the UV exposed substrates was observed to decrease over the wavelength range of $200-\mathrm{nm}$ to $860-\mathrm{nm}$ with each additional UV exposure. The final UV transmittance was about 75 percent of the original transmittance and the decrease in 
transmittance appeared to be independent of amount of NVR believed to be deposited on the substrate as shown in Figures 7,8 , and 9.

Figure 7. The progressive darkening of Sample 15 at various, intermittent exposures.

Figure 8. Sample 15 showing loss of transmittance or substrate darkening.

Figure 9. Sample 17 also showing loss of transmittance or substrate darkening

Sample JSC-B

The "grossly" contaminated sample prepared by JSC, an addition to the original 24 samples, did have strong absorbance bands in the region from $200-\mathrm{m}$ to $320-\mathrm{nm}$, prior to any UV exposure. The transmittance of the sample increased during the first $100 \mathrm{ESH}$ of UV exposure (Figure 10). This increase in transmittance was attributed to a loss of material from the surface of the substrate, possible outgassing, and was not observed in subsequent UV exposure periods. With increased UV exposure the transmittance of the sample, in the wavelength range of 200-nm to 650-nm, continued to decrease and the absorbance bands merged into a single, broad curve after 1077-ESH as shown in Figures 11 through 16.

Figure 10. Sample JSC-B showing an increase in transmittance after the initial exposure to vacuum conditions and $100 \mathrm{ESH}$ of UV. 
Figure 11. UV/VIS Spectra of Sample JSC-B from 0 ESH to 716 ESH.

Figure 12. UV/VIS Spectra of Sample JSC-B from $200 \mathrm{~nm}$ to $850 \mathrm{~nm}$.

Figure 13. UV/VIS Spectra of Sample JSC-B from 716 ESH to 2566 ESH.

Figure 14. UV/VIS Spectra of Sample JSC-B from $200 \mathrm{~nm}$ to $850 \mathrm{~nm}$.

Figure 15. UV/VIS Spectra of Sample JSC-B from 2566 ESH to 6151 ESH

Figure 16. UV/VIS Spectra of Sample JSC-B from $200 \mathrm{~nm}$ to $850 \mathrm{~nm}$.

Kapton Samples 
Two of the samples, \#19 and \#20, differed from the other samples as Kapton tape had been applied to the fused silica substrates before the urine solution was applied to the "composite" substrate. The target NVR deposit on these samples was 500-angstroms per square cm, similar to the NVR deposits on samples \#13 and \#14 without the Kapton layer. These "composite" samples have a broad absorbance band from $200 \mathrm{~nm}$ to $650 \mathrm{~nm}$ which is attributed to the Kapton tape(Figures 17 and 18).

Figure 17. UV/VIS Spectrum of Sample 19.

Figure 18. Section of interest from the composite curve of Sample 19.

\section{Conclusions}

A measurable decrease, maximized at $200-\mathrm{nm}$, of approximately 25 -percent in optical transmittance was observed over the wavelength range of $200 \mathrm{~nm}$ to $900 \mathrm{~nm}$ for the fuse silica substrates used in this study; as the exposure to the UV source progressed. No significant changes in the solar absorbance, infrared emittance, sample mass, or transmittance (200-nm to $2500-\mathrm{nm})$ were measured for urine deposits of 1000 -angstroms or less. A single urine deposit at the $\mathrm{mg} / \mathrm{cm}^{2}$ level did undergo a measurable decrease in transmittance as the UV exposure progressed.

Spectra of urine deposited on Kapton, applied over the fused silica substrates used in this study, did show a small change in transmittance (200-nm to $2500-\mathrm{nm})$. Similar urine 
deposits placed directly on the fused silica substrates did not undergo the same change in transmittance, suggesting that the change can be attributed to the Kapton layer.

The darkening of the urine deposits, as measure spectrographically, may be affected by the morphology or the concentration of the urine deposits. It was assumed that the urine deposits would form a semi-uniform film across the surface of the substrates. Elipsometer measurements of the urine deposits were inconclusive, for deposits of 1000 angstroms or less, and no attempt to characterize the morphology of the $\mathrm{mg} / \mathrm{cm}^{2}$ sample was made. It is possible, but not demonstrated in this study, that a threshold may exist for either the detection of the urine on the fused silica substrates or the UV induced change in transmittance.

\section{Acknowledgments}

George Wertz, NASA, George C. Marshall Space Flight Center, Brian Mayeaux, NASA, Lyndon B. Johnson Space Center, David Moore and Rodrigo Riveria, Lockheed Martin Corporation, Lyndon B. Johnson Space Center, 


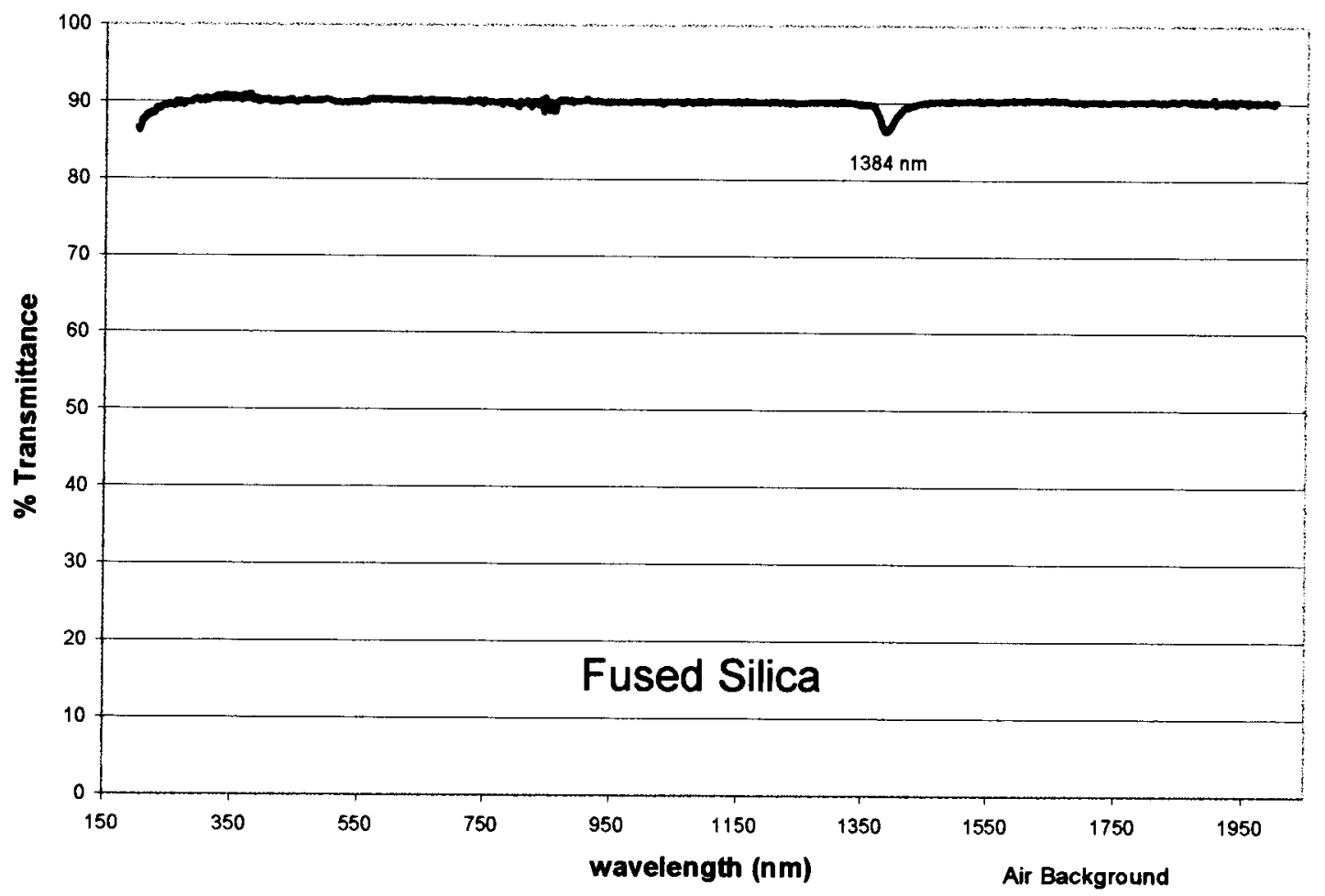

Figure 1. Ultra Violet/Visible Light (UV/VIS) Spectrometer scan of the fused silica substrate 200-nm to 2500-nm. Ambient laboratory air was used as the background for the scan. 


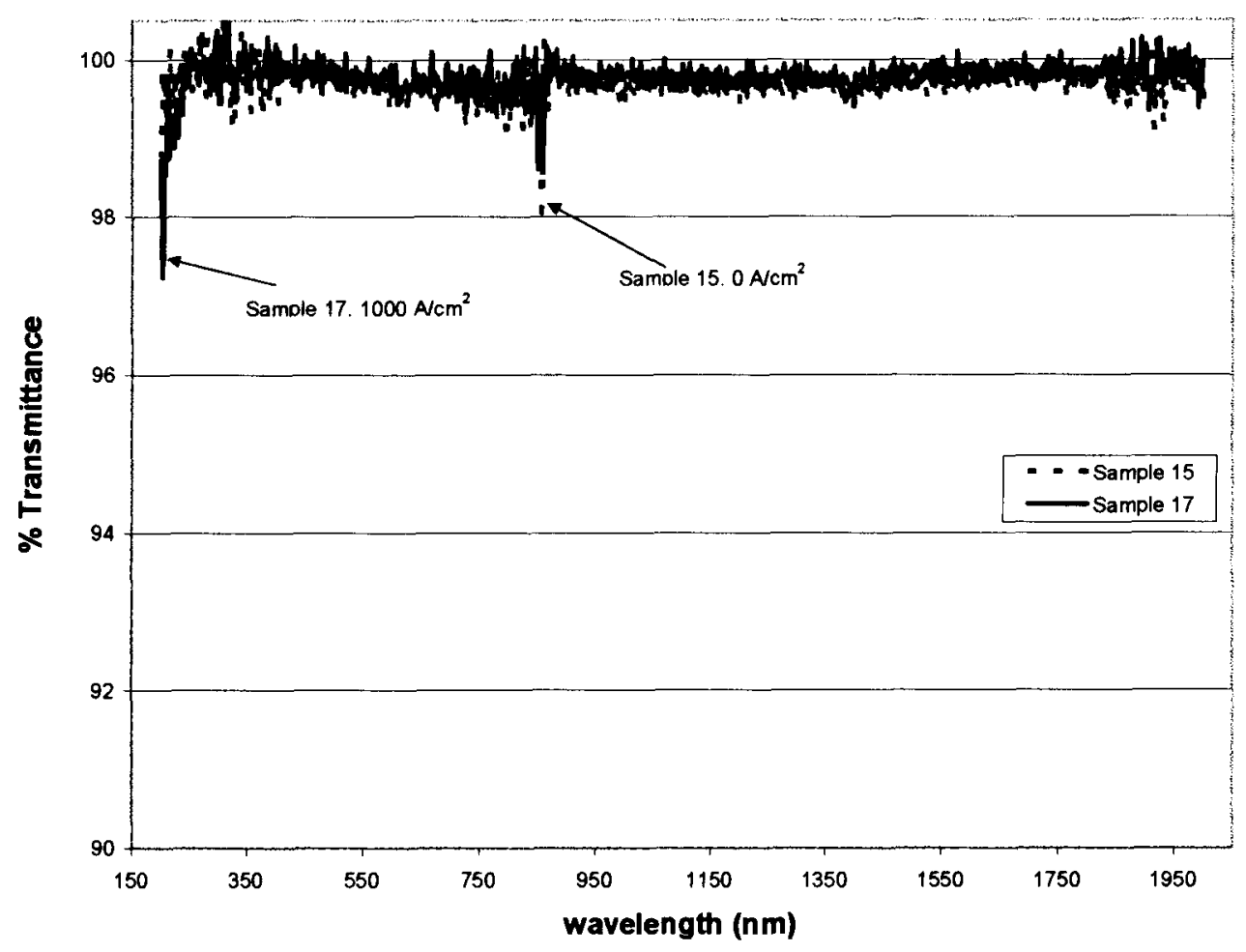

Figure 2. Samples \#15 and \#17 prior to UV exposure. 


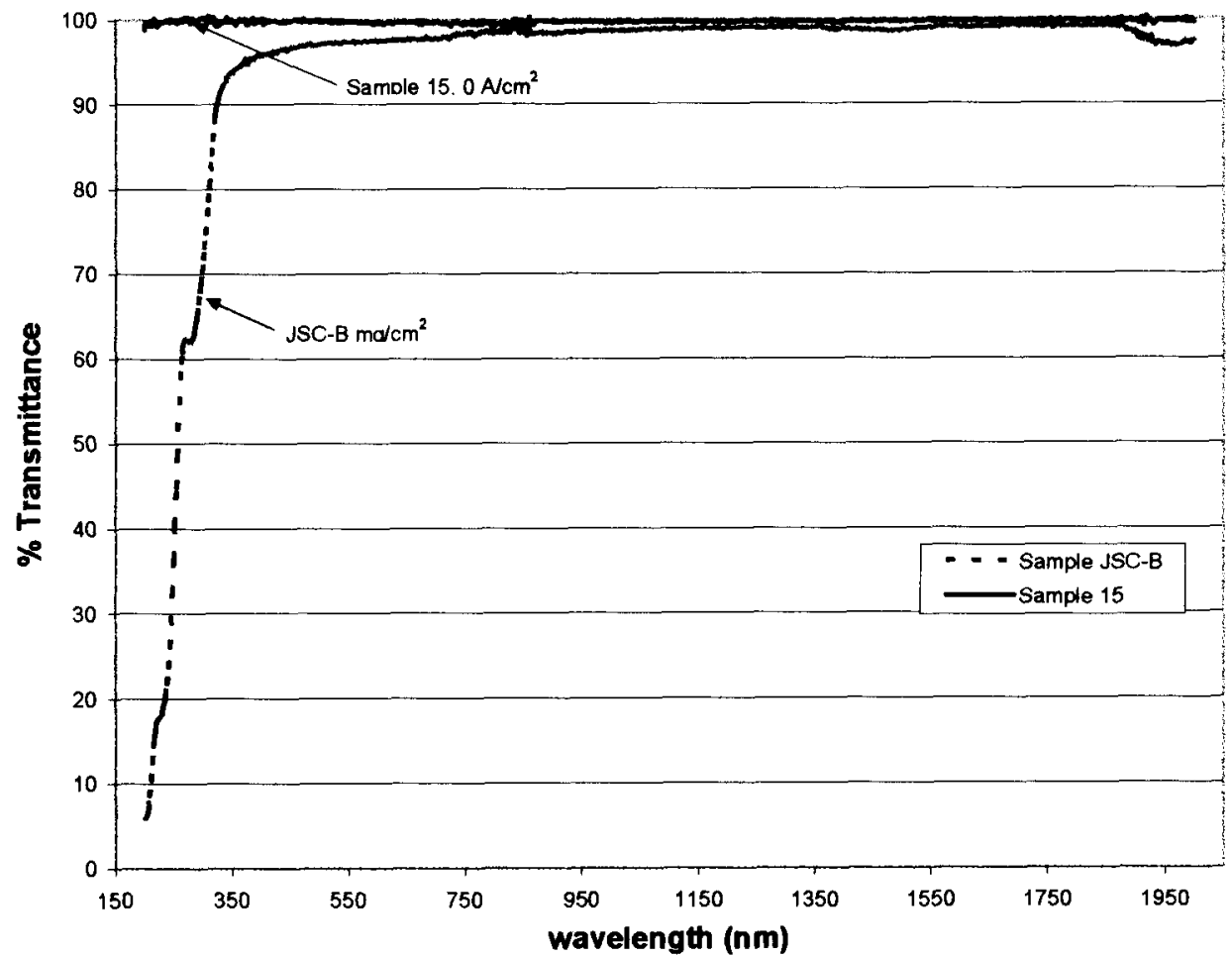

Figure 3. UV/VIS Scan of sample JSC-B prior to UV exposure. 


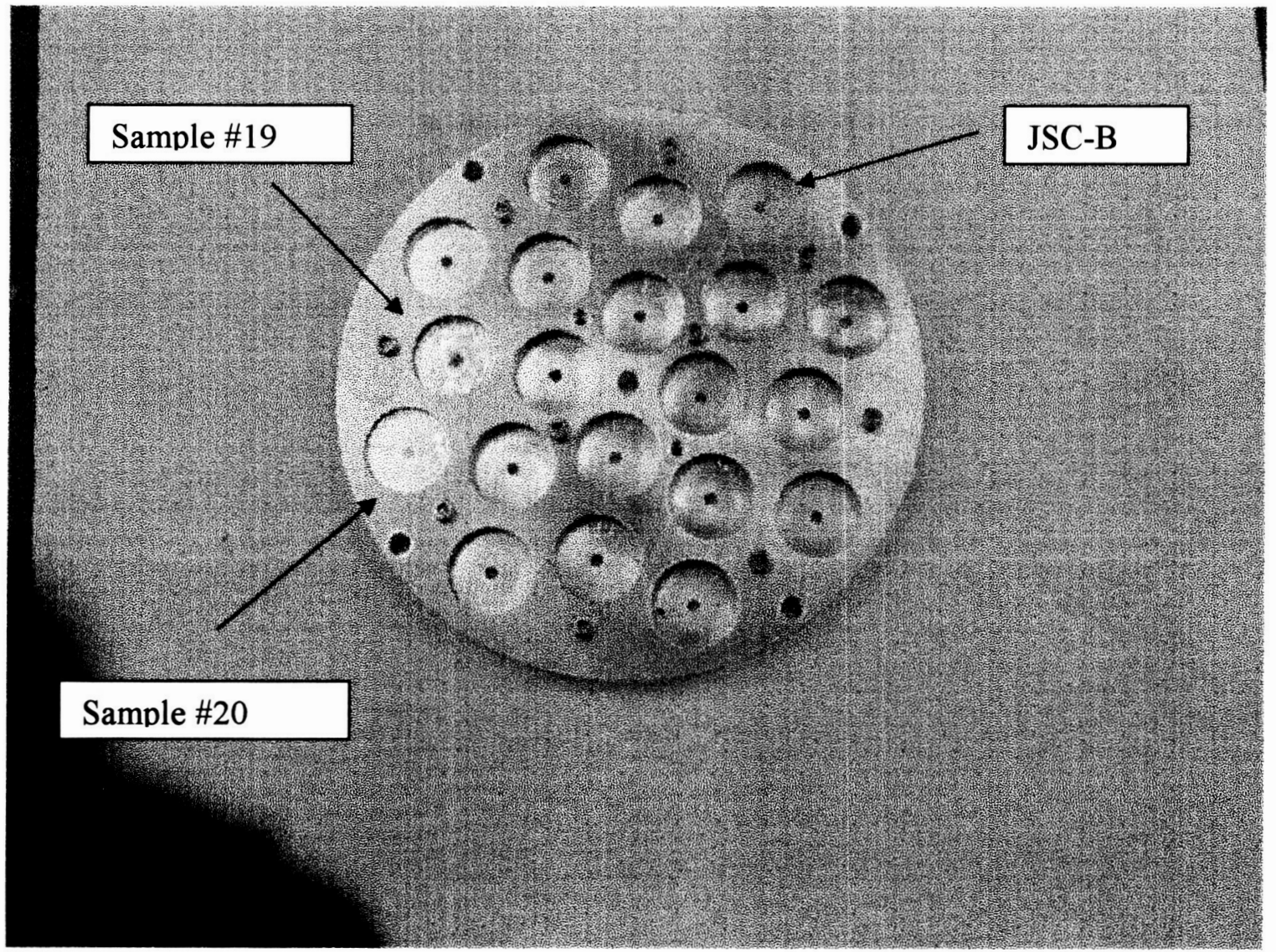

Figure 4. The sample holder with the fused silica sample disks as they appeared after approximately $6151 \mathrm{ESH}$ of UV exposure. On the left-hand side of the sample holder (9 and 10 o'clock positions) are samples \#19 and \# 20. The dark sample at the upper right-hand side of the sample holder (1 o'clock) is Sample JSC-B. 


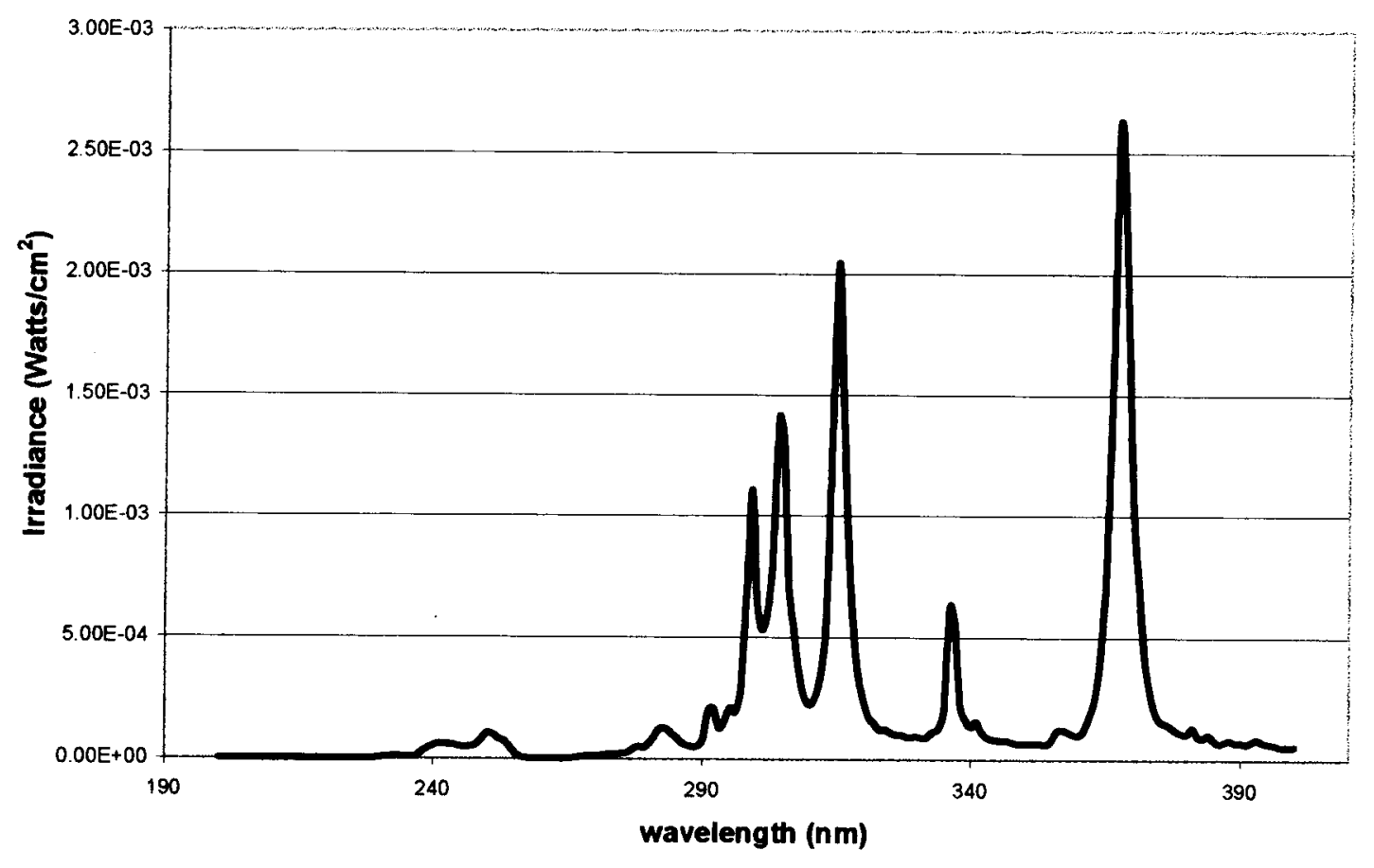

Figure 5. UV Lamp Spectrum. Major peaks at $304 \mathrm{~nm}, 315 \mathrm{~nm}$, and $376 \mathrm{~nm}$. 


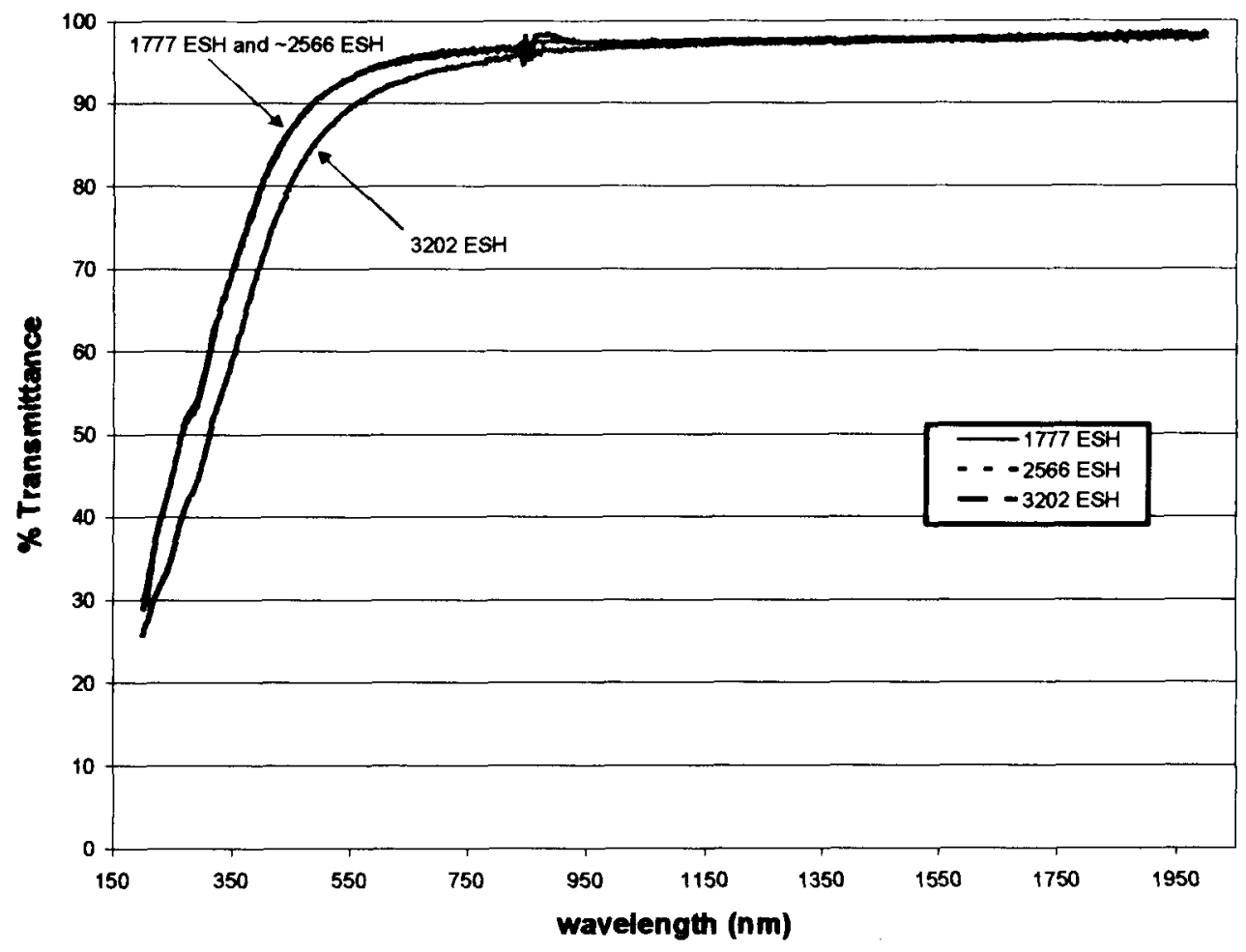

Figure 6. Scans of JSC-B prior to and after the UV-lamp failure. 


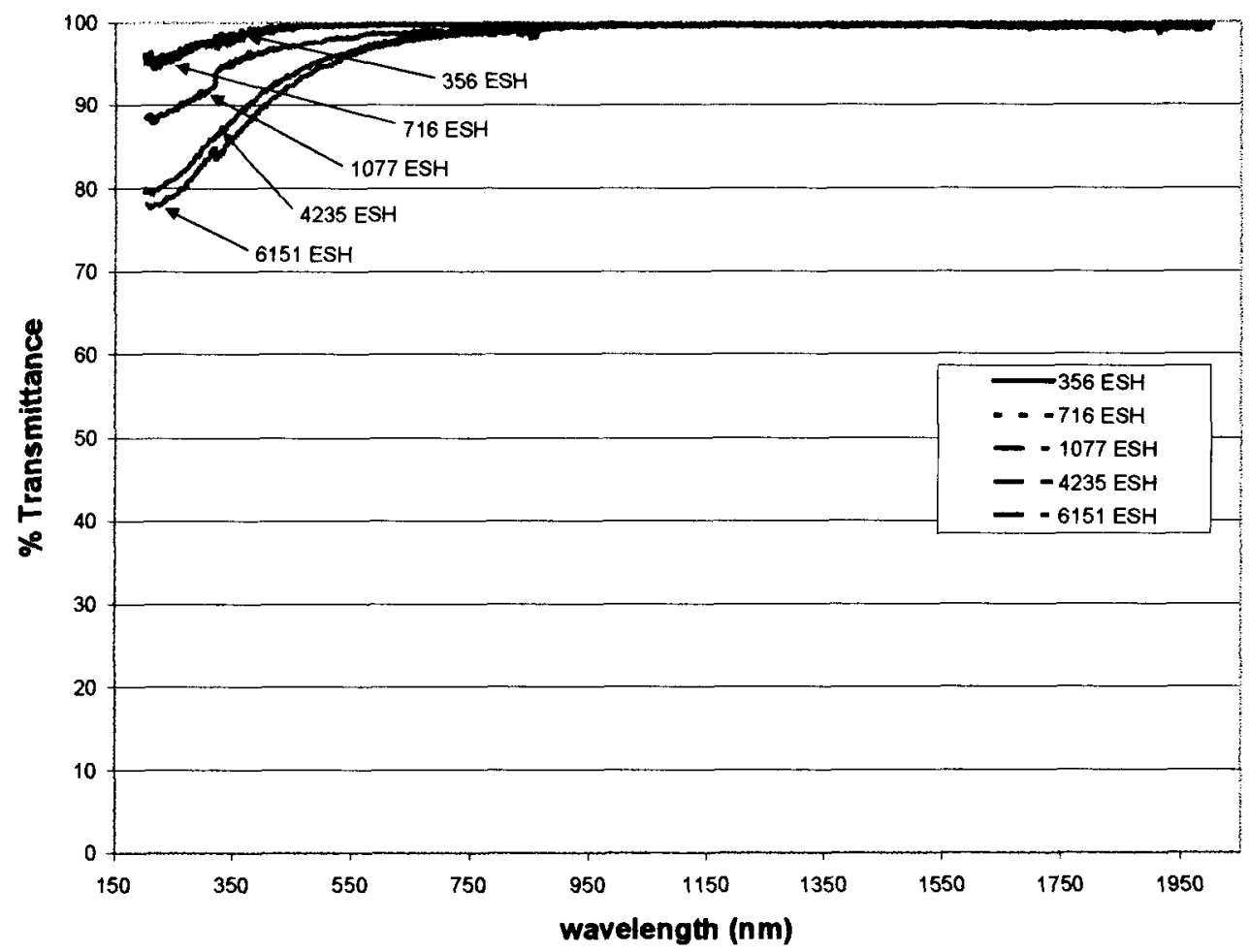

Figure 7. The progressive darkening of Sample 15 at various, intermittent exposures. 


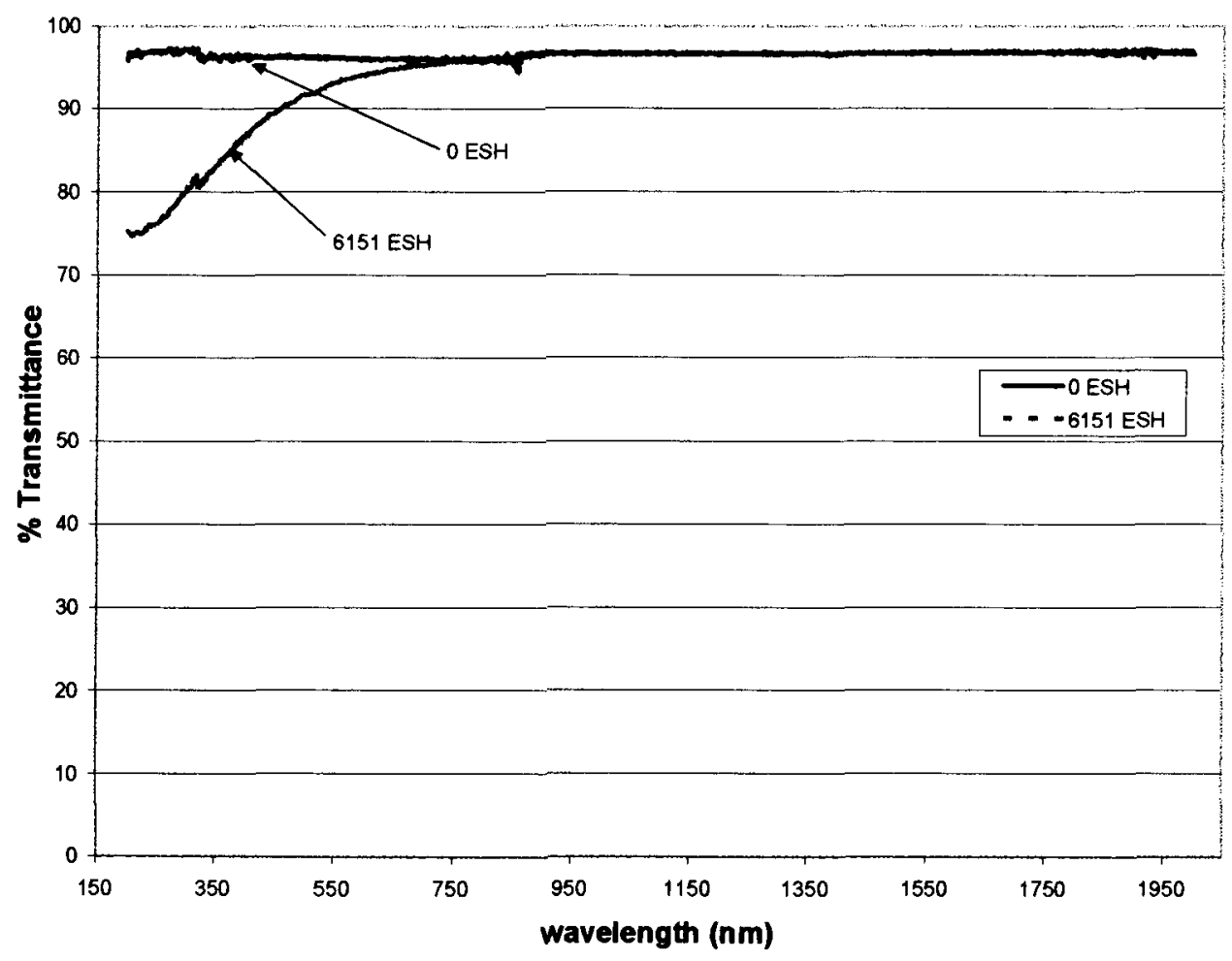

Figure 8. Sample 15 showing loss of transmittance or substrate darkening. 


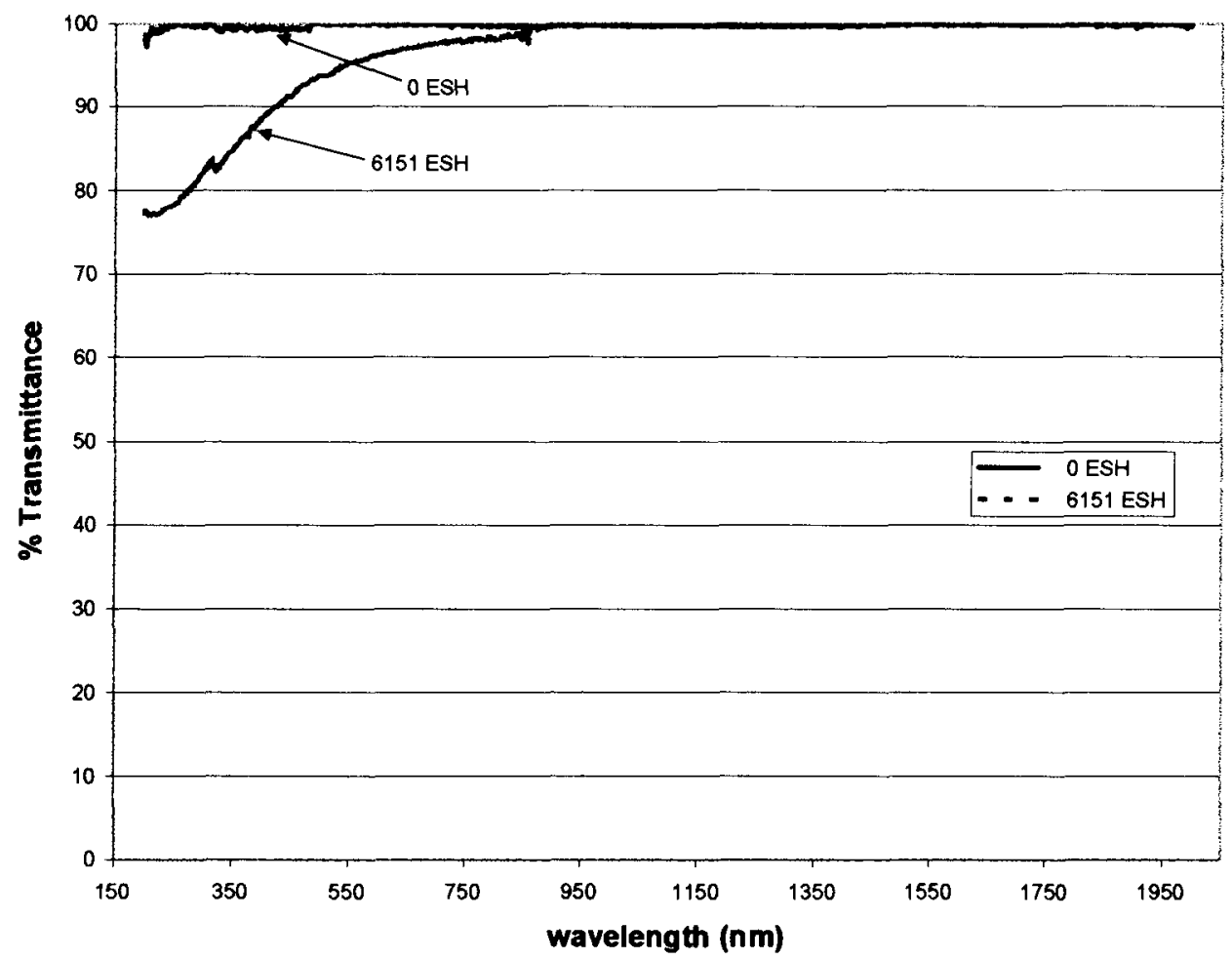

Figure 9. Sample 17 also showing loss of transmittance or substrate darkening. 


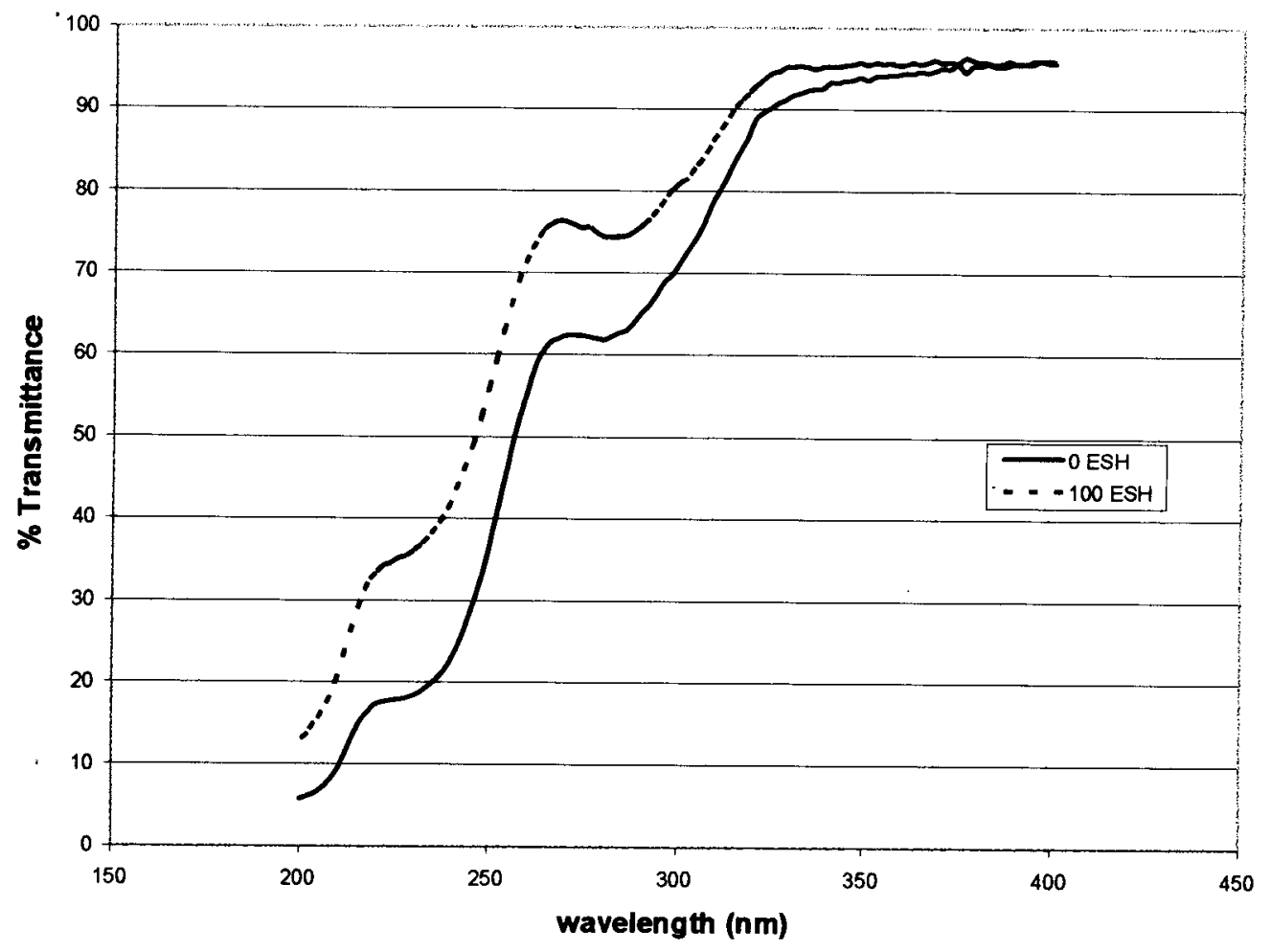

Figure 10. Sample JSC-B showing an increase in transmittance after the initial exposure to vacuum conditions and $100 \mathrm{ESH}$ of UV. 


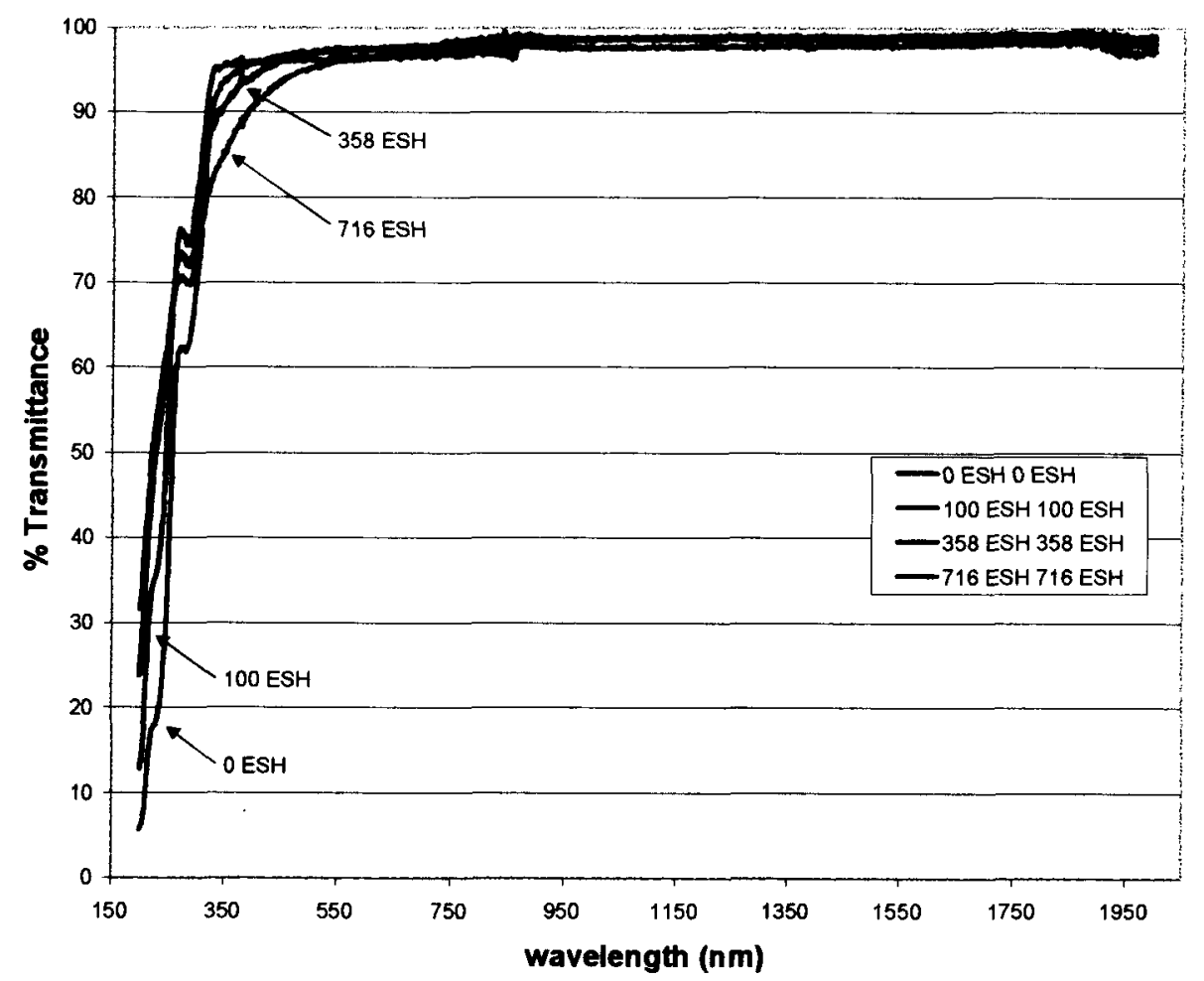

Figure 11. UV/VIS Spectra of Sample JSC-B from 0 ESH to 716 ESH. 


\section{5/07/03 7:42 AM}

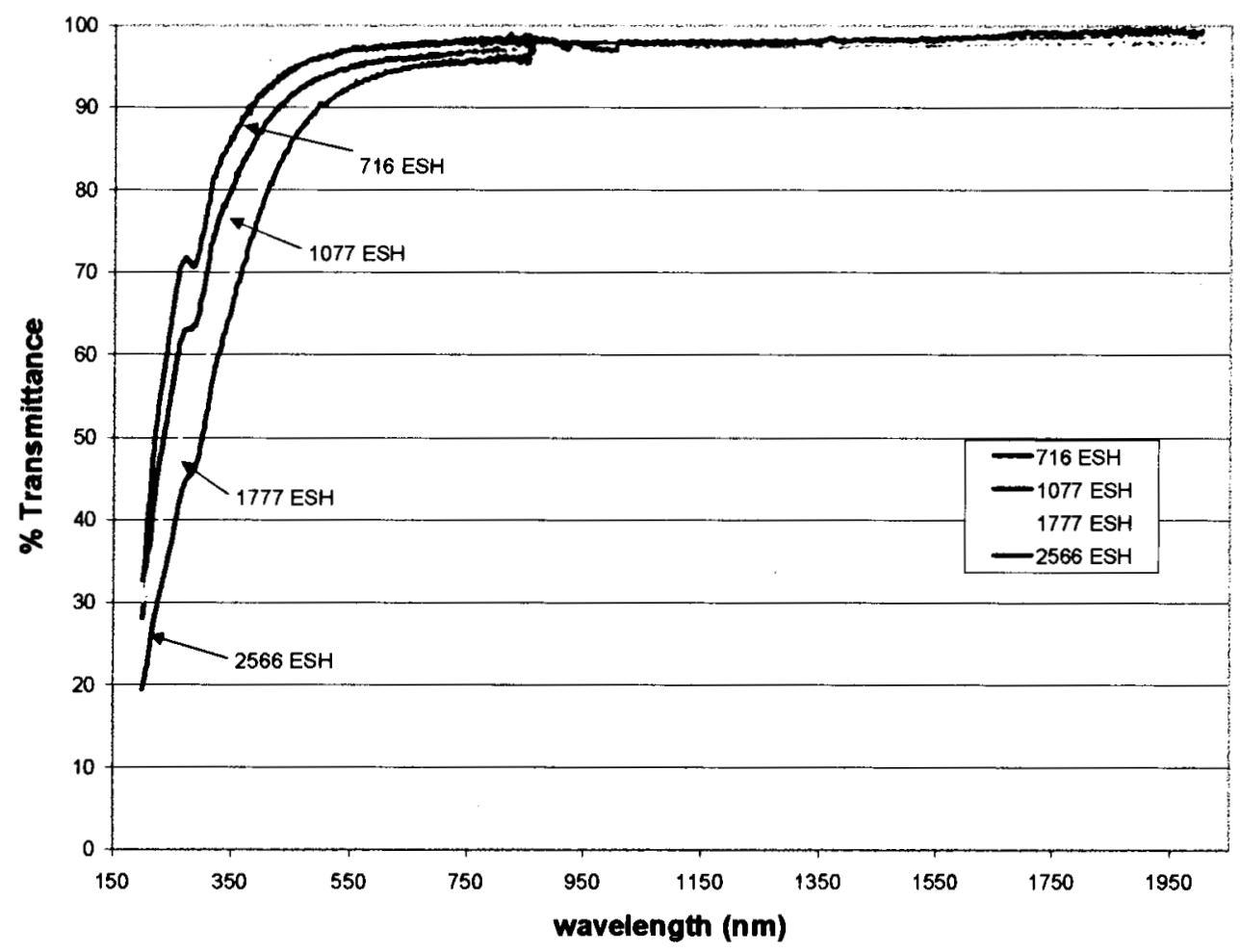

Figure 12. UV/VIS Spectra of Sample JSC-B from $200 \mathrm{~nm}$ to $850 \mathrm{~nm}$. 


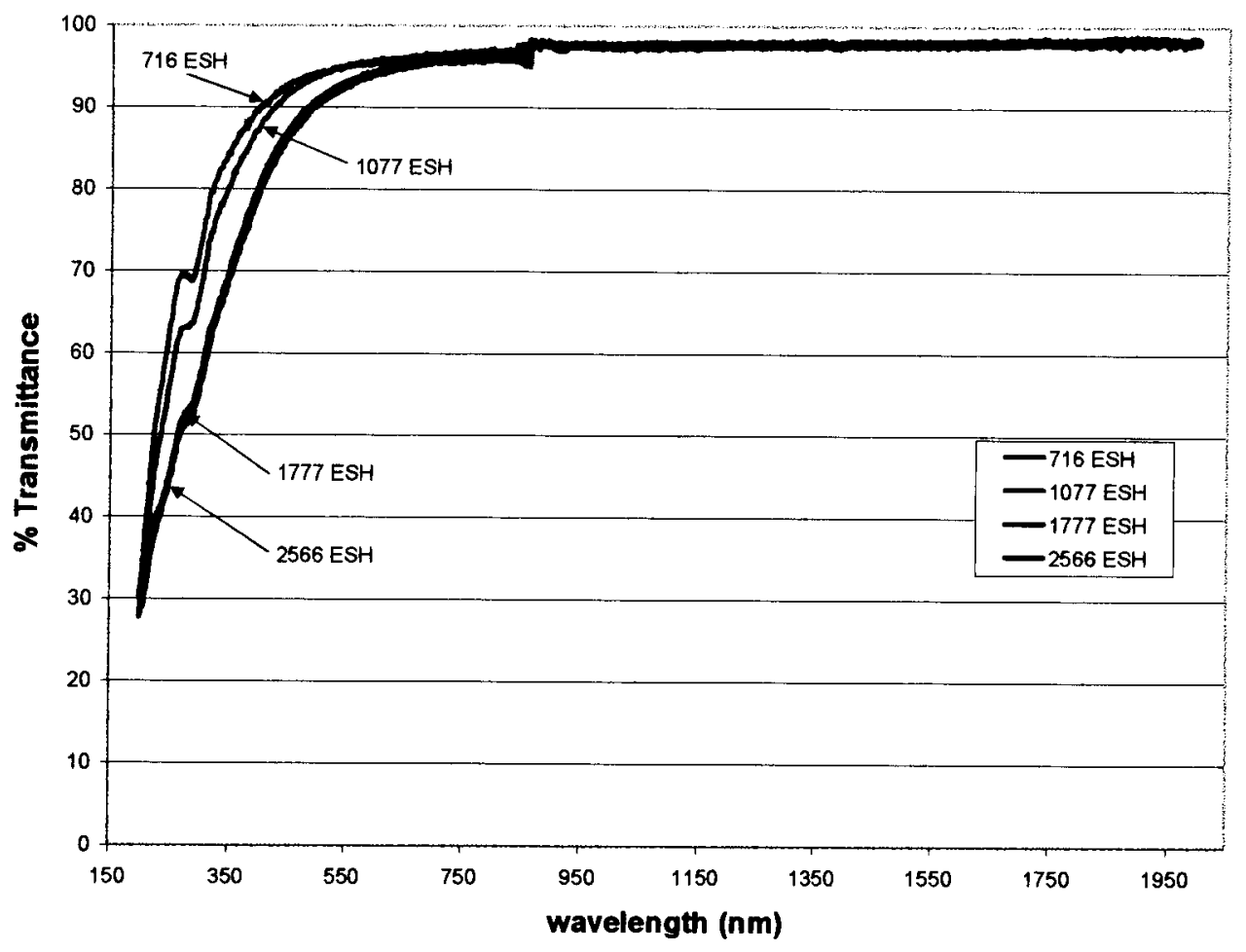

Figure 13. UV/VIS Spectra of Sample JSC-B from 716 ESH to 2566 ESH. 


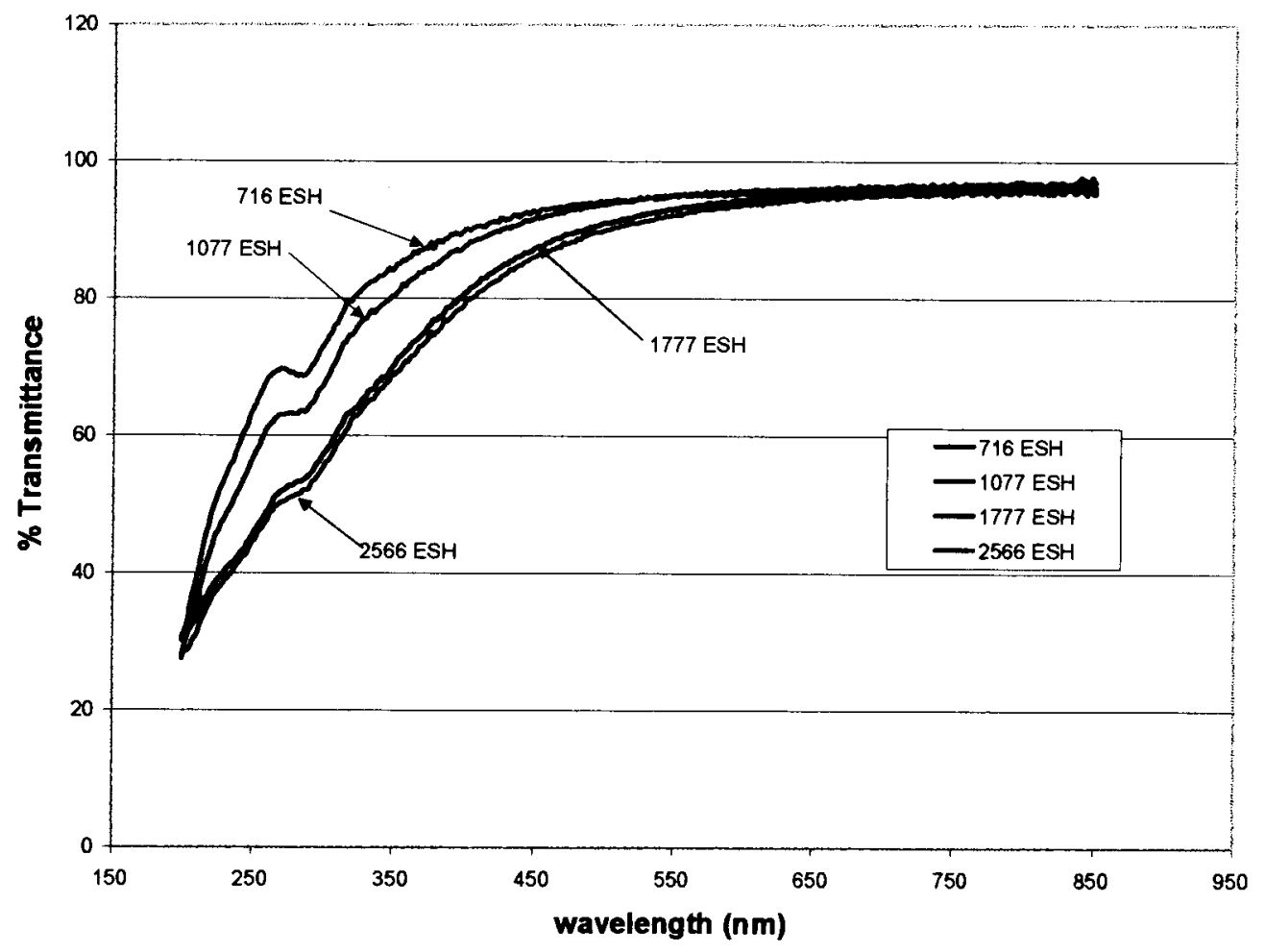

Figure 14. UV/VIS Spectra of Sample JSC-B from $200 \mathrm{~nm}$ to $850 \mathrm{~nm}$. 


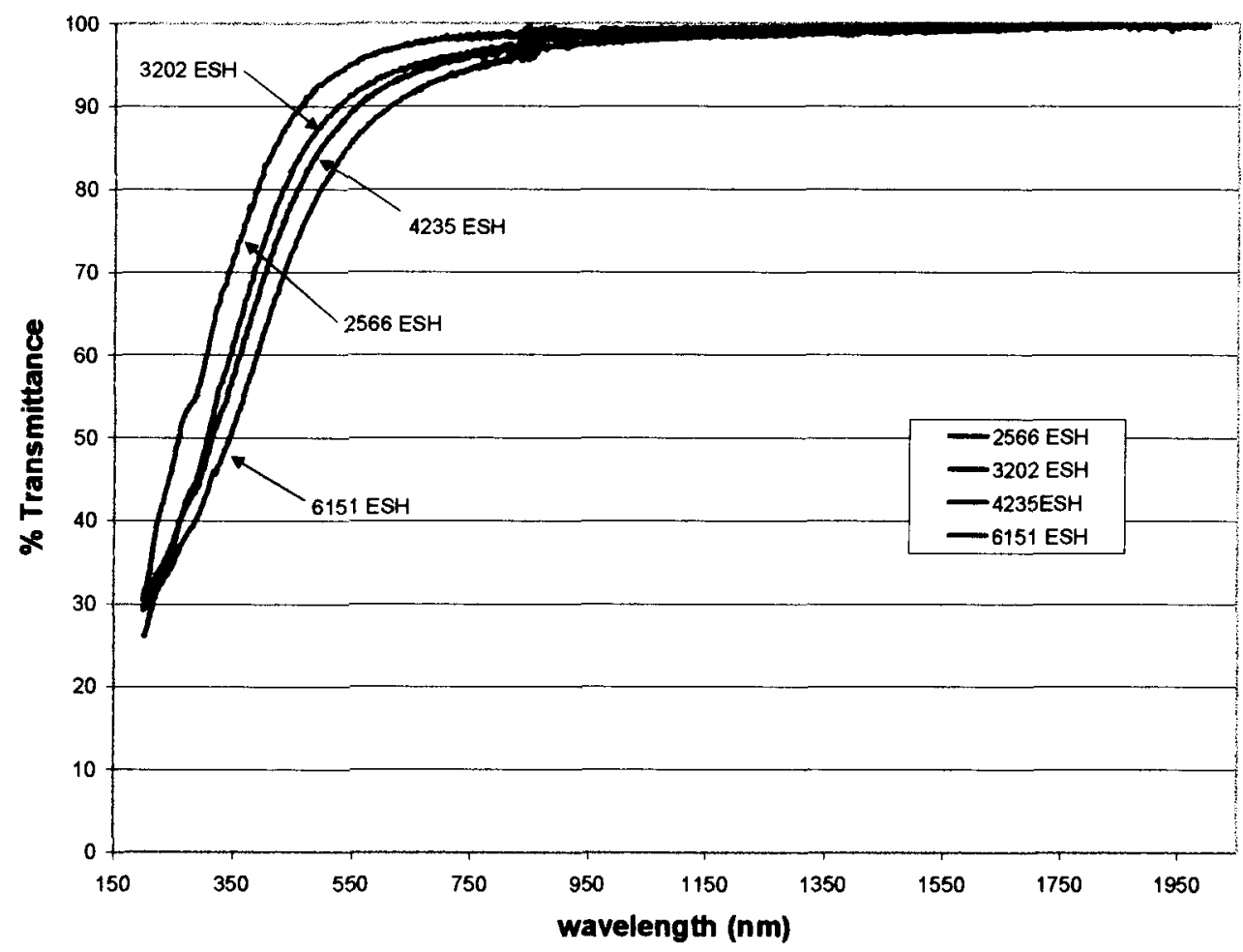

Figure 15. UV/VIS Spectra of Sample JSC-B from 2566 ESH to 6151 ESH 
a

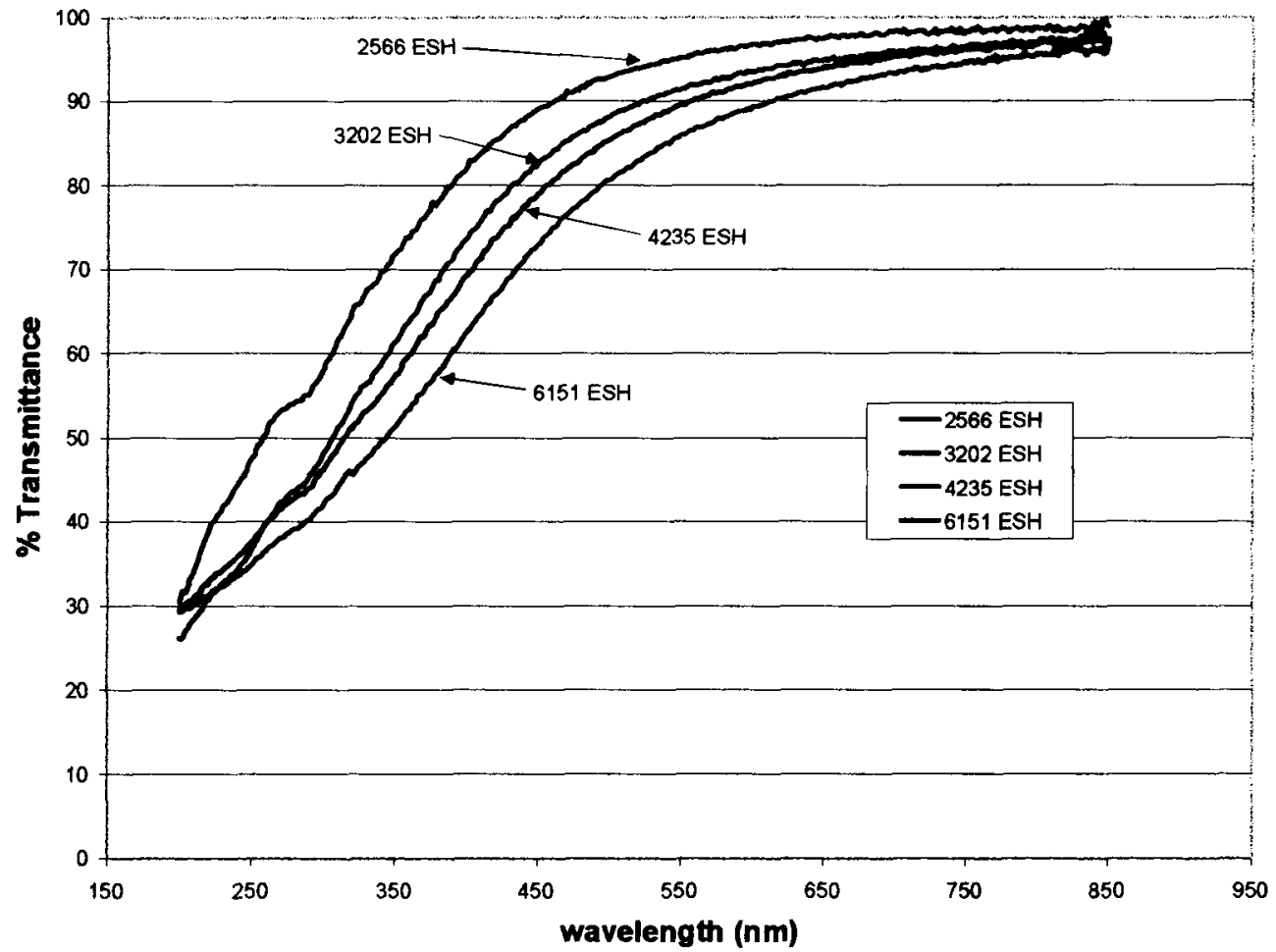

Figure 16. UV/VIS Spectra of Sample JSC-B from $200 \mathrm{~nm}$ to $850 \mathrm{~nm}$. 


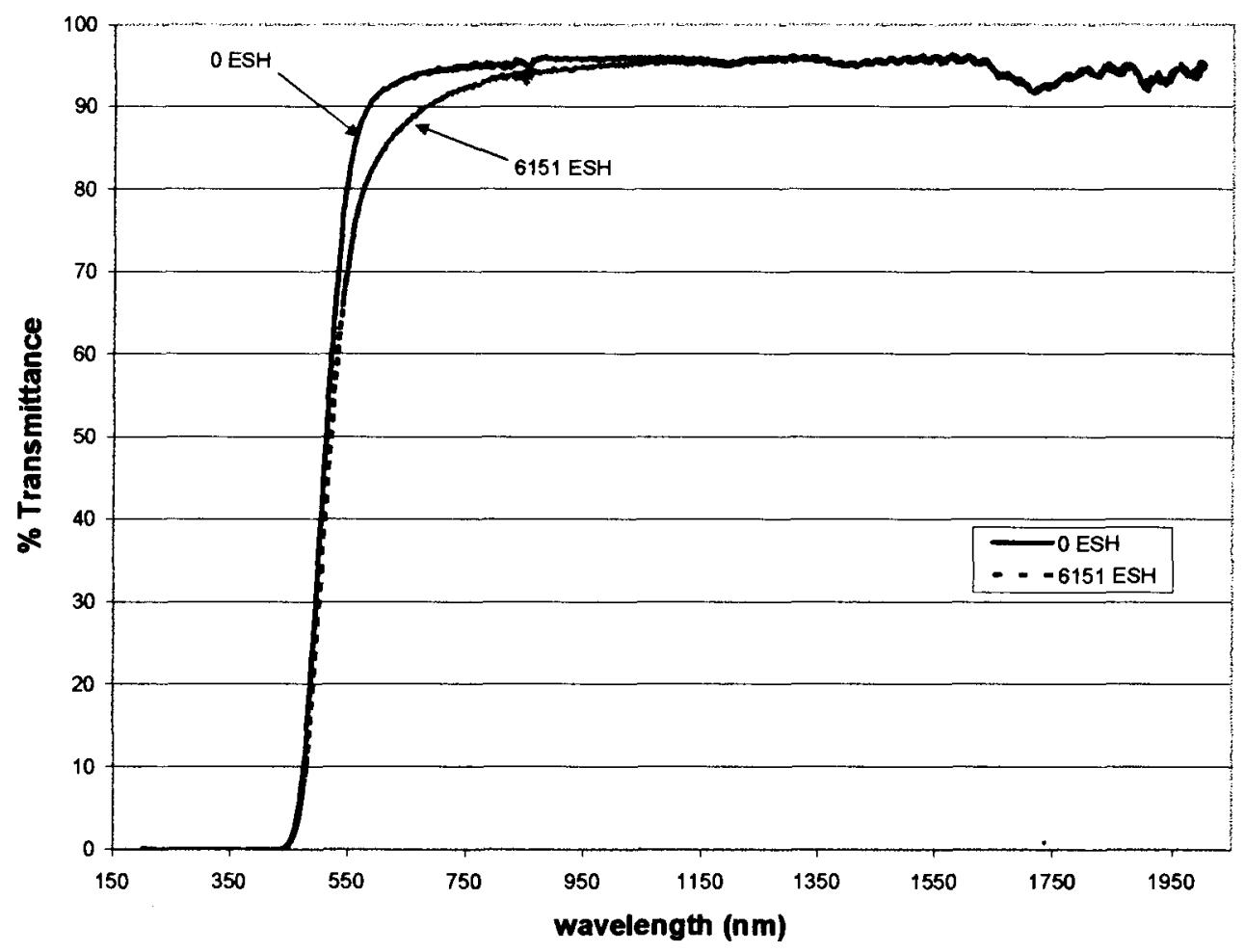

Figure 17. UV/VIS Spectrum of Sample 19. 


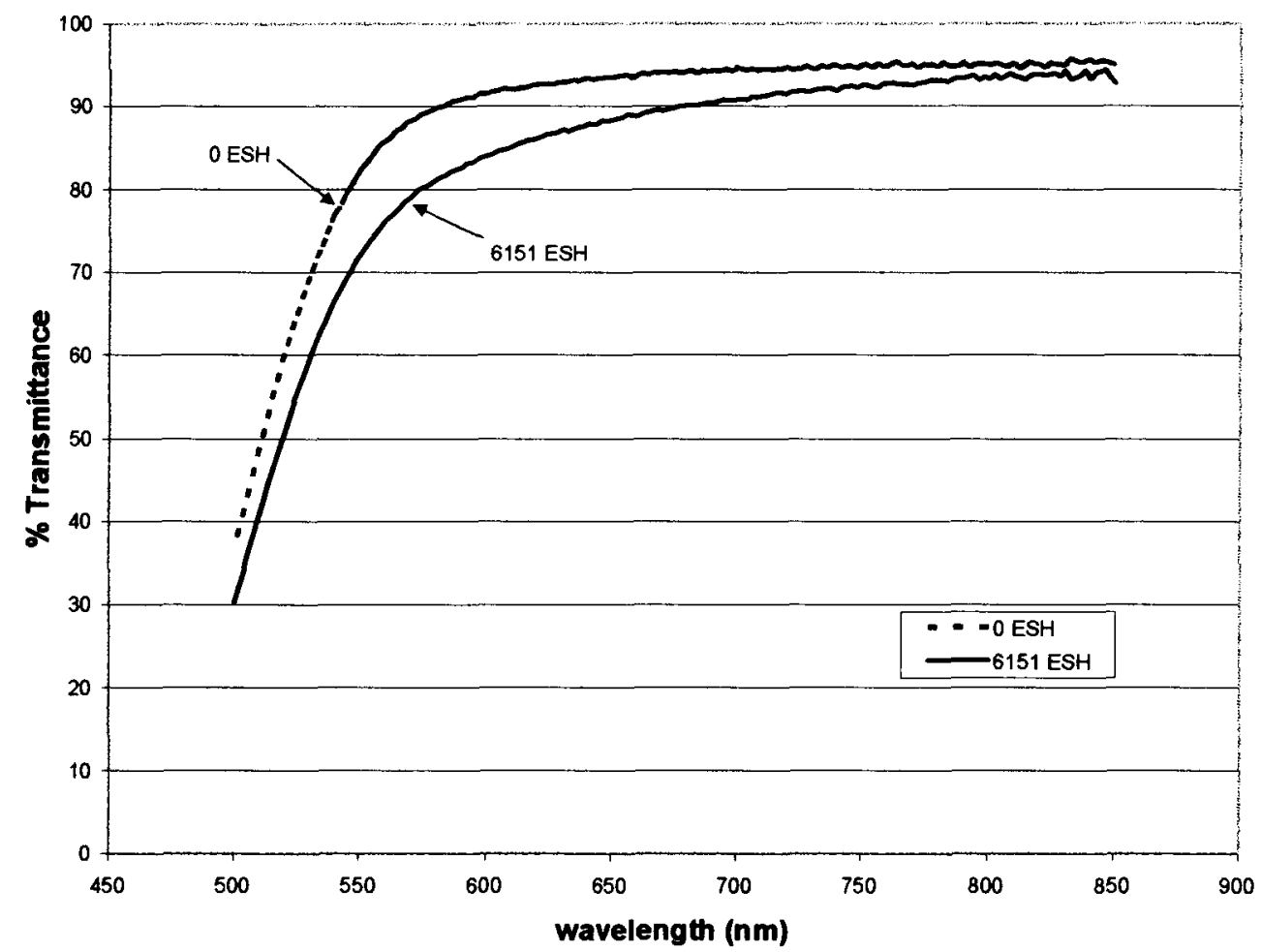

Figure 18. Section of interest from the composite curve of Sample 19. 